Available online on 15.7.2018 at http://ujpr.org
Universal Journal of Pharmaceutical Research
An International Peer Reviewed Journal
Open access to Pharmaceutical research

\title{
PREVALENCE, ANTIMICROBIAL SUSCEPTIBILITY PATTERN AND RISK FACTORS OF MRSA ISOLATED FROM CLINICAL SPECIMENS AMONG MILITARY PATIENTS AT 48 MEDICAL COMPOUND IN SANA'A CITY- YEMEN
}

Ahmed Mohammed Ali Al-Safani ${ }^{1,2}{ }^{D}$, Hassan A. Al-Shamahy ${ }^{1 *}$, Khaled A. Al-Moyed $^{1}$ (D) ${ }^{\prime}$ Medical Microbiology and Clinical Immunology, Faculty of Medicine and Health Sciences, Sana'a University, Yemen. ${ }^{2} 48$ Medical Compound, Ministry of Defense, Republic of Yemen, Sana'a city-Yemen.

\section{ABSTRACT}

Objective: Methicillin-resistant strains of $S$. aureus evolved in the 1970 and have troubled hospitals worldwide with persistent infections in patients. The objectives of this study were to determine the prevalence, antimicrobial susceptibility pattern and risk factors of MRSA isolated from clinical specimens among military patients at 48 Medical Compound in Sana'a city - Yemen.

Methods: The study included 233 patients of whom suffering from Staphylococcus aureus infections. Specimens and data collected from November 2016 to November 2017. Standard methods of isolation and identifications were used to isolate bacteria in pours culture then Staphylococcus aureus were identifying using standard cultural techniques. MRSA was determined by the disc diffusion method to oxacillin and antimicrobial susceptibility testing was performed by the disc diffusion method for selected antibiotics.

Results: The prevalence rate of MRSA was $19.3 \%$ and there was significant association between MRSA and older age patients, and surgical site infections. There was higher rate of antibiotics resistant for tested antibiotics in MRSA isolates comparing with lower rate of antibiotics resistant in MSSA. 60\% of the MRSA isolates were resistant to vancomycin. They were also susceptible to erythromycin and rifampicin (100\%), but showed resistance to Cotrimoxazole and Gentamycine.

Conclusion: In conclusion, the emergence of $S$. aureus isolates resistant to vancomycin and other wide range of antibiotics have raised MRSA in Yemen into a multi-drug-resistant 'Superbug", making it more and more dangerous than ever in hospital environments. Regular surveillance of hospital associated infections and monitoring antibiotic sensitivity pattern and strict drug policy for antibiotics used within and outside the hospital environments are recommend.

Keywords: MRSA, MSSA, MDR, Superbug, Sana'a city, Yemen.

Article Info: Received 7 April 2018; Revised 29 May; Accepted 27 June, Available online 15 July 2018

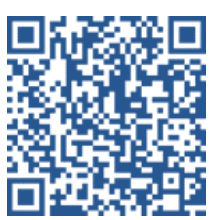

Cite this article-

Al-Safani AMA, Al-Shamahy HA, Al-Moyed KA. Prevalence, antimicrobial susceptibility pattern and risk factors of MRSA isolated from clinical specimens among military patients at 48 medical compound in Sana'a city-Yemen. Universal Journal of Pharmaceutical Research 2018; 3(3): 39-43.

DOI: https://doi.org/10.22270/ujpr.v3i3.165

Address for Correspondence:

Prof. Hassan A. Al-Shamahy, Medical Microbiology and Clinical Immunology, Faculty of Medicine and Health Sciences, Sana'a University, Yemen. E-mail: shmahe@yemen.net.ye, Tel: +967-770299847.

\section{INTRODUCTION}

Staphylococcus aureus (S. aureus) is a bacterium of significant importance because of its ability to cause a wide range of diseases and capacity to adapt to diverse environmental forms ${ }^{1}$. The organism colonizes skin, skin glands and mucous membrane, causing infections both in human and animals such as rashes, inflammations of bones and the meninges as well as septicaemia ${ }^{2}$. At present, the majority of $S$. aureus strains are resistant to most penicillin derivatives and ordinary antimicrobial agents like drugs from the family of aminoglycosides, macrolides, chloramphenicol, tetracyclines and fluoroquinolones ${ }^{3}$. The global spread of MRSA constitutes one of the most serious contemporary challenges to the treatment of hospitalacquired infections ${ }^{4}$. MRSA carries a uniquely effective antibiotic resistance mechanism that can protect the microorganisms against all members of $\beta$-lactam antibiotics. This makes infections caused by these pathogens very difficult to manage and costly to treat $^{5,6}$.

The objectives of this study were to determine the prevalence, antimicrobial susceptibility pattern and risk factors of MRSA isolated from clinical specimens among military patients at 48 Medical Compound in Sana'a city-Yemen. 


\section{SUBJECTS AND METHODS}

\section{Ethical Consideration}

Ethical clearance for the study was taken from the Faculty of Medicine and Health Sciences Research Review Committee. A written permission was also taken from the administrative Manager of the 48 Medical Compound, Sana'a city, Yemen. Informed Consent was taken from the patients before the questionnaire was filled.

Table 1: The prevalence of MSSA and MRSA among isolated coagulase positive (S. aureus) in Sana'a city.

\begin{tabular}{lcc}
\hline Organisms & Number & Percentage \\
\hline MSSA & 188 & 80.7 \\
MRSA & 45 & 19.3 \\
Total S. aureus & 233 & 100 \\
\hline
\end{tabular}

Survey procedure and Laboratory Analysis This study was conducted during a period of one year, starting in November 2016 and ending in November 2017 at 48 Medical compounds in Sana'a city-Yemen. All clinical specimens were received and collected by laboratory department of the hospital. 233 isolates of $S$. aureus were isolated from all age groups of out- or inpatients hospitalized in different wards. Clinical specimens were taken from various body sites of infection including blood, wound, sputum, urine and others. Clinical and demographic data were collected for all participants' patients. Clinical specimens were collected using standard collection techniques ${ }^{7,8}$, and inoculated on appropriate bacteriological media, including blood agar, chocolate agar, Thioglycollate, Mac-Conkey Agar Media. The plates were incubated aerobically at $37^{\circ} \mathrm{C}$ for $18-24 \mathrm{~h}$. The blood cultures were performed using an automated blood culture system, followed by bacterial growth inspection. The identification of isolates was made according to standard methods ${ }^{9}$ for any potential clinically significant growth appear on the culture media on the base of quantity, feature of growth, source and site of specimens. The primary identification was made with basic microbiological methods using colony morphology, Gram staining, catalase and coagulase tests $^{7}$.

Table 2: The potential associated risk factors of MRSA in patients with S.aureus infection in Sana'a city.

\begin{tabular}{|c|c|c|c|c|c|c|c|c|}
\hline \multirow{2}{*}{ Factors } & \multicolumn{2}{|c|}{ MRSA } & \multicolumn{2}{|c|}{ MSSA } & \multirow[t]{2}{*}{ OR } & \multirow[t]{2}{*}{ CI } & \multirow[t]{2}{*}{$\chi^{2}$} & \multirow[t]{2}{*}{$p$} \\
\hline & No. & $\%$ & No. & $\%$ & & & & \\
\hline In-patients $n=103$ & 20 & 19.4 & 83 & 80.6 & 1.0 & $0.5-1.97$ & 0.001 & 0.97 \\
\hline Out-patients $n=130$ & 25 & 19.2 & 105 & 80.8 & 0.98 & $0.5-1.9$ & 0.001 & 0.97 \\
\hline \multicolumn{9}{|l|}{ Age Median (24 years) } \\
\hline $\begin{array}{r}<24 \text { years } \\
n=104\end{array}$ & 13 & 12.5 & 89 & 85.6 & 0.45 & $0.23-0.9$ & 5 & 0.02 \\
\hline $\begin{array}{c}>24 \text { years } \\
n=129\end{array}$ & 32 & 24.8 & 99 & 76.7 & 2.2 & $1.1-4.5$ & 5 & 0.02 \\
\hline \multicolumn{9}{|l|}{ Clinical specimens } \\
\hline $\begin{array}{l}\text { Surgical wound pus } \\
\mathrm{n}=39\end{array}$ & 9 & 23.1 & 30 & 76.9 & 1.3 & $0.6-3.2$ & 0.6 & 0.43 \\
\hline Nonsurgical wounds pus $n=77$ & 13 & 16.9 & 64 & 83.1 & 0.78 & $0.36-1.6$ & 0.43 & 0.51 \\
\hline Pleural fluid $n=5$ & 1 & 20 & 4 & 80 & 1.04 & $0.11-9.5$ & 0.002 & 0.96 \\
\hline Sputum $n=23$ & 3 & 13 & 20 & 87 & 0.6 & $0.17-2.1$ & 0.64 & 0.42 \\
\hline Surgical site infections (SSI) & 7 & 33.3 & 14 & 66.7 & 2.3 & $1.0-6$ & 3.9 & 0.05 \\
\hline Wound and pus $n=21$ & & & & & & & & \\
\hline Urine culture $n=41$ & 6 & 14.6 & 35 & 85.4 & 0.67 & $0.26-1.7$ & 0.69 & 0.4 \\
\hline Bone pus $n=27$ & 6 & 22.2 & 21 & 77.8 & 1.2 & $0.46-3.2$ & 0.16 & 0.68 \\
\hline
\end{tabular}

\begin{abstract}
Antibiotic Resistance Phenotypes (Methicillin/ Oxacillin susceptibility testing): All the Staphylococcus aureus isolates were tested for the susceptibility to $5 \mu \mathrm{g}$ Methicillin disc and $1 \mu \mathrm{g}$ Oxacillin disc provided by Difco using the disk diffusion method as described by NCCLS. The resistance breakpoints were $\geq 14 \mathrm{~mm}$ to $\leq 10 \mathrm{~mm}$ for $5 \mu \mathrm{g}$ Methicillin, and $\geq 12$ $\mathrm{mm}$ to $\leq 10 \mathrm{~mm}$ for $1 \mu \mathrm{g}$ Oxacillin. The ability of other antibiotic disc to inhibit MRSA or MSSA were estimated according to the guidelines provided by NCCLS using commercially available discs which include: azithromycine (AZM, 15 $\mu \mathrm{g}$ ), chloramphenicol $(\mathrm{C}, 30 \mu \mathrm{g})$, gentamycine $(\mathrm{GN}, 10 \mu \mathrm{g})$, trimethoprim-

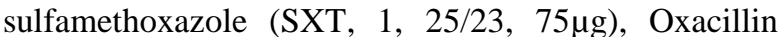
$(\mathrm{OX}, 1 \mu \mathrm{g})$, erythromycin $(\mathrm{E}, 15 \mu \mathrm{g})$, cefoxitin (FOX,

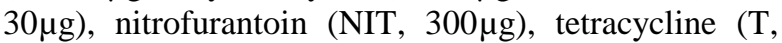
$30 \mu \mathrm{g}$ ), teicoplanin (TE, 30 $\mu \mathrm{g}$ ), clindamycin (CC, $2 \mu \mathrm{g})$,

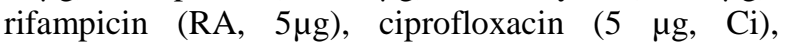
vancomycin $(\mathrm{V}, 30 \mu \mathrm{g})$ and others listed in Table 4.
\end{abstract}

\section{Data analysis}

The analysis of data was done by Epi Info version 6 statistical program (CDC, Atlanta, USA), where the chi-square $\left(\chi^{2}\right)$ and probability value $(p)$ was calculated for the test of significance. In addition, Odd's ratio (OR), confidence interval (CI) were added to estimate the risk factors of contracting MRSA.

\section{RESULTS}

Table 1, Table 2, and Table 3 show the prevalence of MSSA and MRSA among isolated coagulase positive ( $S$. aureus), the potential associated factors of MRSA in patients with $S$. aureus infection and the association between prevalence of MRSA and type of hospital wards. Also, the susceptibility pattern of $S$. aureus strains is presented in Table 4 . The prevalence rate of MRSA was $19.3 \%$ and there was significant association between MRSA and older age patients, and surgical site infections. There was higher rate of 
antibiotics resistant for tested antibiotics in MRSA isolates comparing with lower rate of antibiotics resistant in MSSA. Also, $60 \%$ of the MRSA isolates were resistant to vancomycin. They were also susceptible to erythromycin and rifampicin $(100 \%)$, but showed resistance to Cotrimoxazole and Gentamycine.

Table 3: The association between prevalence of MRSA and type of hospital wards in Sana'a city.

\begin{tabular}{|c|c|c|c|c|c|c|c|c|}
\hline \multirow{2}{*}{$\begin{array}{l}\text { In-patients } \\
\text { Wards }\end{array}$} & \multicolumn{2}{|c|}{ MRSA } & \multicolumn{2}{|c|}{ MSSA } & \multirow[t]{2}{*}{ OR } & \multirow[t]{2}{*}{ CI } & \multirow[t]{2}{*}{$\chi^{2}$} & \multirow[t]{2}{*}{$p$} \\
\hline & No. & $\%$ & No. & $\%$ & & & & \\
\hline $\begin{array}{l}\text { Orthopedic ward } \\
\mathrm{n}=34(33 \%)\end{array}$ & 7 & 20.6 & 27 & 79.4 & 1.1 & $0.39-3.1$ & 0.031 & 0.86 \\
\hline $\begin{array}{l}\text { Urology wards } \\
\mathrm{n}=14(13.5 \%)\end{array}$ & 4 & 28.6 & 10 & 71.4 & 1.5 & $0.45-5.1$ & 0.37 & 0.59 \\
\hline $\begin{array}{l}\text { Internal Medical } \\
\text { wards } \\
\mathrm{n}=7(6.8 \%)\end{array}$ & 1 & 14.3 & 6 & 85.7 & 0.67 & $0.07-5.9$ & 0.12 & 0.72 \\
\hline $\begin{array}{l}\text { Surgical wards } \\
\mathrm{n}=48(46.6 \%)\end{array}$ & 8 & 16.7 & 40 & 83.3 & 0.56 & $0.2-1.5$ & 1.3 & 0.25 \\
\hline
\end{tabular}

Table 4: The antibiotic sensitivity for isolated MRSA and MSSA for tested antibiotics in Sana'a city.

\begin{tabular}{lcccc}
\hline \multirow{2}{*}{ Antibiotics } & \multicolumn{2}{c}{ MRSA, $\mathbf{n}=\mathbf{4 5}$} & \multicolumn{2}{c}{ MSSA, $\mathbf{n}=\mathbf{1 8 8}$} \\
\cline { 2 - 5 } & \% Sensitive & \% Resistant & \% Sensitive & \% Resistant \\
\hline Azithromycin & 66.7 & 33.3 & 60.9 & 39.1 \\
Carbinicillin & 0 & 100 & 100 & 0 \\
Cefotaxime & 25 & 75 & 61 & 39 \\
Cefepime & 44.4 & 55.6 & 65.6 & 34.4 \\
Ceftazidime & 50 & 50 & 50 & 50 \\
Ceftriaxone & 100 & 0 & 61.2 & 34.8 \\
Cefalexin & 49 & 51 & 76.3 & 23.7 \\
Nalidixic acid & 50 & 50 & 46.7 & 53.3 \\
Chloramphenicol & 50 & 50 & 66.7 & 33.3 \\
Ciprofloxacin & 100 & 0 & 61.3 & 38.7 \\
Clindamycin & 0 & 100 & 33.3 & 66.7 \\
Cotrimoxazole & 0 & 100 & 80 & 20 \\
Erythromycin & 100 & 0 & 65.6 & 34.4 \\
Gentamicin & 50 & 50 & 87.5 & 12.5 \\
Nitrofurantoin & 0 & 100 & 71.4 & 28.6 \\
Rifampicin & 100 & 0 & 33.3 & 76.7 \\
Tetracycline & 40 & 60 & 22.2 & 77.8 \\
Ticarcillin & 42.9 & 57.1 & 9.5 & 90.5 \\
Tobramycin & 55 & 45 & 30 & 70 \\
Vancomycin & 60 & 40 & 20 & 80 \\
\hline
\end{tabular}

\section{DISCUSSION}

We detected MRSA in $19.3 \%$ of all Staphylococcus aureus isolates (Table 1). Current study result is lower than that reported from USA in which MRSA was isolated from $59 \%$ of patients with skin and soft tissue infections ${ }^{10}$. Also $19.3 \%$ MRSA of all Staphylococcus aureus isolates is lower than that reported from Yemen in previous reports in which MRSA was isolated from $55 \%$ of HCWs in Taiz city, Yemen ${ }^{11}$ and extremely low from that reported by Al-Baidani et al., ${ }^{12}$ among HCWs in Hodeida city, Yemen in which the MRSA rate was $86 \%$. In addition, the prevalence of MRSA among inpatients (HA-MRSA) was $19.4 \%$ roughly similar to $19.2 \%$ among outpatients (CA-MRSA) (Table 2). Prolonged hospital stays, indiscriminate use of antibiotics, lack of awareness, and receipt of antibiotics before coming to the hospital are some of the possible predisposing factors of MRSA emergence in the hospital and community. Current result is different from that reported from USA in which high rate of MRSA was occurred in hospital acquired $S$. aureus infections (HA-MRSA) (59\%), than in community acquired infection $S$. aureus $(17 \%)^{13}$. This variation can be explained by that the biology of CA-
MRSA appears to differ from that of HA-MRSA and CA-Methicillin-susceptible $S$. aureus (MSSA), perhaps allowing CA-MRSA to cause disease other than that expected from MSSA ${ }^{14,15}$. As HA-MRSA emerged, it likely did not merely replace HA-MSSA but led to an overall increase in $S$. aureus infections in healthcare settings ${ }^{16,17}$. In addition nearly all the researchers say the same thing that in-patients and outpatients have higher $S$. aureus/ MRSA infections than $S$. aureus/MSSA because of wide spread of MRSA in community and hospitals environment ${ }^{17,18,19}$.

When it was considered that age as risk factor of MRSA in current study, the highest incidence of MRSA in current study's cases were in age groups of $>$ median (24 years). The risk age group of in-patients and out-patients in current study was different from that reported previously in several studies in which roughly equal rates of MRSA in the different age groups $^{20}$. In current study when it was considered that the association between prevalence of MRSA and sites of infections (type of clinical specimens), the highest prevalence MRSA was $33.3 \%$ in surgical site infection (SSI) with associated odds ratio equal to $2.2(P>=$ 0.05) (Table 2). The general pattern of MRSA 
infections in this study is not different from that worldwide in which in MRSA in surgical site infection (SSI) was one of the major diagnosis infections by MRSA $^{20}$. This study was carried out because of the knowledge of MRSA prevalence and the current antimicrobial profile is necessary in selection of appropriate empirical treatment of these infections and control of MRSA in hospitals is essential. In current study vancomycin resistant was $40 \%$ in isolated MRSA. This result is different from that reported in Asian countries in which the rate of vancomycin resistant was not more than $10 \%{ }^{21}$. Also the incidence of VRSA in the Asian countries has been documented by Kaleem et al., ${ }^{22}$ in Pakistan to be $3.3 \%$, 6\% in India, by Sonavane and Mathur ${ }^{23}, 7.5 \%$ in Iran by Mehdinejad et al., ${ }^{24}$, and $9 \%$ in Jordan by Al-Zoubi et al. ${ }^{3}$.

The results of current study shows a higher rate of resistant of MRSA comparing with a study carried out at India in 2009 which showed variable susceptibility pattern with high resistance rates to tetracycline (82\%), clindamycin $(79 \%)$, and cotrimoxazole $(59 \%)$, while in current study all MRSA were sensitive to rifampicin different to $50 \%$ of rifampicin resistant in India ${ }^{25}$. On other hand resistance to chloramphenicol $(50 \%)$ and naldixic acid $(50 \%)$ was lower than Indian studies in which resistance to chloramphenicol was $10 \%$ and naldixic acid was $9 \%^{25}$. Studies carried out at by Kishore et al., ${ }^{26}$ in India, by Kaleem et al., ${ }^{22}$ in Pakistani and by Al-Zoubi et al., ${ }^{3}$ in Jordan showed that less than $10 \%$ of MRSA isolates were sensitive to Macrolides, whereas $38 \%$ of isolates were found to be sensitive in current study. In current study $100 \%$ of the MRSA isolates were sensitive to ciprofloxacin which is harmonized with the results of India, Pakistani, Iranian and Jordan studies in which ciprofloxacin also found to be $100 \%$ sensitive to all MRSA isolates $3,22,26,27$. Effective antimicrobial activity as well as cost effectiveness should be considered in drugs prescribed for MRSA infections. Oral dosing options for antibiotics can allow earlier discharge of hospitalized patients and minimize the chances of VRSA emergence. Good hospital infection control measures prove to be the main stay against these infections because antibiotics can never be an effective alternative to good medical practice. Also, medium sensitivity percentages were found to gentamycine, trimethoprimsulfamethoxazole and tetracycline (Table 4). Different sensitivity percentages have been reported to these three antibiotics worldwide ${ }^{28,29,30}$. These differences might be due to prolonged antibiotic treatment, age, type of infection and geographical variation.

\section{CONCLUSION}

In conclusion, the results of this study showed the importance of regular surveillance of hospital associated infections including monitoring antibiotic sensitivity pattern and strict drug policy for antibiotics used within and outside the hospital environments. Moreover, in-vitro susceptibility testing of every isolate of MRSA in the clinical laboratories may be helpful for reducing the incidence of these infections.

\section{ACKNOWLEDGEMENTS}

Authors acknowledge the support of Sana'a University and 48 Medical compounds, Yemen.

\section{AUTHOR'S CONTRIBUTION}

The manuscript was carried out, written, and approved in collaboration with all authors.

\section{CONFLICT OF INTEREST}

No conflict of interest associated with this work.

\section{REFERENCES}

1. Lowy FD. Staphylococcus aureus infections. N Engl J Med. 1998; 339(8):520-532.

2. Aklilu E, Zunita Z, Hassan L, Chen HC. Phenotypic and genotypic characterization of Methicillin-resistant Staphylococcus aureus (MRSA) isolated from dogs and cats at University Veterinary Hospital, University Putra Malaysia. Trop. Biomed 2010; 27(3): 483-492. PMID: 21399590

3. Al-Zoubi, MS, Ibrahim Ali Al-Tayyar, Emad Hussein, et al. Antimicrobial susceptibility pattern of Staphylococcus aureus isolated from clinical specimens in Northern area of Jordan. Iran J Microbiol 2015; 7(5): 265-272. PMID: 26719783

4. Szczepanik A, Koziol-Montewka M, Al-Doori Z, Morrison D, Kaczor D. Spread of a single multi-resistant methicillinresistant Staphylococcus aureus clone carrying a variant of staphylococcal cassette chromo-some mec type III isolated in a university hospital. Eur J Clin Microbiol Infect Dis 2007; 26: $29-35$.

https://doi.org/10.1007/s10096-006-0237-5

5. Hiramatsu K, Katayama Y, Yuzawa H, Ito T. Molecular genetics of methicillin-resistant Staphylococcus aureus. Int J Med Microbiol; 2002; 292: 67-74.

https://doi.org/10.1078/1438-4221-00192

6. Aires de Sousa M, De Lencastre H. Bridges from hospitals to the laboratory: genetic portraits of Methicillinresistant Staphylococcus aureus clones. FEMS Immunol Med Microbiol 2004. 8; 40: 101- 11. https://doi.org/10.1016/S0928-8244(03)00370-5

7. Cheesbrough MC. District Laboratory Practice in Tropical Countries. $1^{\text {st }}$ Edn, Cambridge University Press, Cambridge 2006, UK. https://doi.org/10.1017/CBO9780511543470

8. CLSI (Clinical and Laboratory Standards Institute). Performance Standards for Antimicrobia Susceptibility Testing: Nineteenth Informational Supplement. CLSI document M100-S19; 2009.

9. Layer F, Ghebremedhin B, Moder KA, Konig W, Konig B. Comparative study using various methods for identification of Staphylococcus species in clinical specimens. J Clin Microbiol 2006. 44: 2824-2830. https://doi.org/10.1128/JCM.00226-06

10. Krishnadasan A, et al. Methicillin- resistant $S$. aureus infections among patients in the emergency department. $\mathrm{N}$ Engl J Med 2006; 355:666-74. https://doi.org/10.1056/NEJMoa055356

11. Abdel Monem, M.O. Nasal Carriage of Staphylococcus aureus among Healthcare Workers in Althawra Hospital, Taiz City, Republic of Yemen. Australian J Basic Applied Sciences 2012; 6(7): 417-424. https://doi.org/10.1016/j.sciaf.2020.e00325

12. Al-Baidani AR, El-Shouny WA and Shawa TM. Antibiotic susceptibility of MRSA in three hospitals at Hodeida city Yemen. Globle J Pharma 2011; 5(2):106-111. https://doi.org/10.15537/smj.2019.3.23947

13. Fridkin SK, Hageman JC, Morrison M, Sanza LT, ComoSabetti K, Jernigan JA, et al. Methicillin-resistant Staphylococcus aureus disease in three communities. N Engl J Med 2005; 352:1436-44. Erratum in: N Engl J Med 2005; 352:2362. https://doi.org/10.1056/NEJMoa043252 
14. Askarian M, Zeinazadeh A, Japoni A, et al. Prevalence of nasal carriage o Methicillin resistance Staphylococcus aureus and its antibiotic susceptibility pattern in healthcare workers at Namazi Hospital, Shiraz, Iran. Int J Infect Dis 2009; 13:e241-e247. https://doi.org/10.1016/j.ijid.2008.11.026

15. Mahalingam U, Thirunvukarasu T, Murugananthan K. Methicillin resistant Staphylococcus aureus among nurses in a tertiary care hospital in Sri Lanka. Ceylon Medical J 2014; S9:63-65. https://doi.org/10.4038/cmj.v59i2.7067

16. Elie-Turenne MC, et al. Prevalence and characteristics of Staphylococcus aureus colonization among healthcare professionals in an urban teaching hospital. Infection Control and Hospital Epidemiology 2010; 31:S74-S80 https://doi.org/10.1086/652525

17. Radhakrishna M, D'Souza M, Kotigadde S, VishwasSaralaya K, Shashidar-Kotian M. Prevalence of methicillin resistant Staphylococcus aureus carriage amongst health care workers of critical care units in Kasturba Medical College Hospital, Mangalore, India. J Clin Diagnostic Res 2013; 7(12):2697-2700.

https://doi.org/10.7860/JCDR/2013/5160.3735

18. Shibabaw A, Abebe T, Mihret A. Nasal carriage rate of methicillin-resistant Staphylococcus aureus among Dessie Referral hospital health care workers; Dessie Northeast, Ethiopia. Antimicrobial Resistance and Infection Control. 2013; 2:25. https://doi.org/10.1186/2047-2994-2-25

19. Iyer A, Kumosani T, Azhar E, Barbour E, Harakeh S. High incidence rate of methicillin-resistant Staphylococcus aureus among healthcare workers in Saudi Arabia. J Infect Dev Ctnes 2014; 8(3):372-378 https://doi.org/10.18683/germs.2018.1137

20. Tacconelli E, et al. Does antibiotic exposure increase the risk of methicillin-resistant Staphylococcus aureus (MRSA) isolation? A systematic review and meta-analysis". J Antimicrob Chemother 2008; 61 (1): 26-38. https://doi.org/10.1093/jac/dkm416

21. Mehmood A, Butt T, Usman M. A study on MRSA isolates to detect reduced susceptibility to vancomycin: A preliminary report. Infect Dis J 2007; 16:102-104. PMID: 22347563
22. Kaleem F, et al. Sensitivity pattern of methicillin resistant Staphylococcus aureus isolated from patients admitted in a tertiary care hospital of Pakistan. Iran J Microbiol 2010; 2(3): 143-146. PMID: 22347563

23. Sonavane A, Mathur M. Screening for vancomycin intermediate-resistant Staphylococcus aureus among clinical isolates of MRSA. Indian J Med Microbiol 2007; 25:79-80. https://doi.org/10.1086/317542

24. Mehdinejad M, Sheikh AF, Jolodar A. Study of methicillin resistance in Staphylococcus aureus and species of coagulase negative Staphylococci isolated from various clinical specimens. Pak J Med Sci 2008; 24:719-24.

25. Idrees F, Jabeen K, Khan MS, Zafar A. Antimicrobial resistance profile of methicillin resistant staphylococcal aureus from skin and soft tissue isolates. J Pak Med Assoc 2009; 59:266-269. https://doi.org/10.1016/j.foodcont.2005.09.013

26. Kishore S Deepika Verma, ME Siddique. Comparison of invitro activities of linezolid and vancomycin against Staphylococcus aureus isolated from a tertiary care hospital. J Clin Diagn Res 2014; 8(5): DC12-DC15.

https://doi.org/10.7860/JCDR/2014/7751.4338

27. Fatholahzadeh B, Emaneini M, Gilbert G, et al. Staphylococcal cassette chromosome mec ( $\mathrm{scc} \mathrm{mec}$ ) analysis and antimicrobial susceptibility patterns of methicillinresistant Staphylococcus aureus (MRSA) Isolates in Tehran, Iran. Microb Drug Resist 2008; 14: 217-220. https://doi.org/10.1089/mdr.2008.0822

28. Rajaduraipandi K, Mani KR, Panneerselvam K, Mani M, Bhaskar M, Manikandan P. Prevalence and antimicrobial susceptibility pattern of methicillin resistant Staphylococcus aureus: a multicentre study. Indian I Med Microbiol 2006; 24: 34-38. https://doi.org/10.4103/0972-5229.58542

29. Hafeez R, C A, Aslam M. Prevalence and Antimicrobial Susceptibility of Methicillin Resistant Staphylococcus aureus (MRSA). IJP. 2004; 2(1):10-15.

30. Babakir-Mina M, Othman N, Najmuldeen $\mathrm{HH}$, et al. Antibiotic susceptibility of vancomyin and nitrofurantoin in Staphylococcus aureus isolated from burnt patients in Sulaimaniyah, Iraqi Kurdistan. The New Microbiologica 2012; 35: 439-446. PMID: 23109011 